\title{
A VIVÊNCIA DO LUTO EM VIÚVAS IDOSAS: UM ESTUDO CLÍNICO-QUALITATIVO
}

\author{
Adriano Luiz da Costa Farinasso ${ }^{1}$ \\ Renata Curi Labate ${ }^{2}$
}

Este estudo objetiva compreender os significados da vivência do luto em idosas, pela morte do cônjuge/marido. Trata-se de um estudo clínico-qualitativo, realizado em uma amostra intencional, composta por seis viúvas idosas. Os dados foram coletados por meio de entrevista não estruturada e observação. Após análise de conteúdo foram elencadas as seguintes categorias: 1) luto e saudade; 2) histórico de perdas e resiliência; 3) negação como mecanismo de defesa no luto; 4) luto mediado pela culpa; e 5) depressão como reação à perda. Ressalta-se a importância destes significados como alicerce para atuação do profissional de saúde que trabalha com idosos enlutados.

Descritores: Pesar; Idoso; Pesquisa Qualitativa.

\footnotetext{
${ }^{1}$ PhD, Professor Adjunto, Universidade Estadual de Londrina, Londrina, PR, Brasil.

2 PhD, Professor Doutor, Escola de Enfermagem de Ribeirão Preto, Universidade de São Paulo, Centro Colaborador da OMS para o Desenvolvimento da Pesquisa em Enfermagem, Ribeirão Preto, SP, Brasil.
}

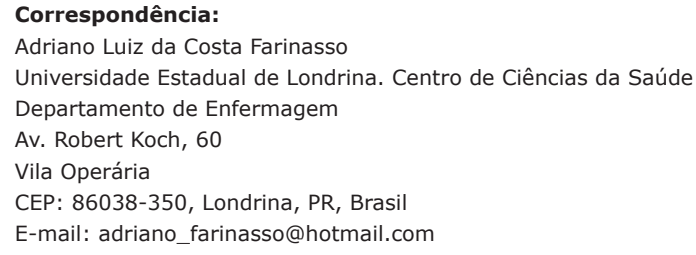




\section{THE BEREAVEMENT EXPERIENCE IN ELDERLY WIDOWS: A CLINICAL- QUALITATIVE STUDY}

This study aims to understand the significance of grief in the elderly by the death of the spouse/husband. This is a clinical-qualitative study that was conducted with an intentional sample, composed of six elderly widows. Data was collected through unstructured interviews and observation. After data analysis was conducted the following categories were listed: 1) grief and longing, 2) history of losses and resilience, 3) denial as a defense mechanism in mourning, 4) mourning mediated by guilt, and 5) depression as a reaction to loss. We emphasize the importance of these findings as a foundation for the practice of health professionals working with bereaved elderly.

Descriptors: Grief; Aged; Qualitative Research.

\section{LA EXPERIENCIA DEL LUTO EN VIUDAS DE LA TERCERA EDAD: UN ESTUDIO CLÍNICO-CUALITATIVO}

Este estudio tiene como objetivo comprender los significados de la experiencia del luto en personas de la tercera edad, por la muerte del cónyuge/marido. Se trata de un estudio clínico-cualitativo, realizado en una muestra intencional, compuesta por seis viudas de la tercera edad. Los datos fueron reunidos por medio de entrevista no estructurada y mediante la observación. Tras el análisis de contenido fueron enumeradas las siguientes categorías: 1) luto y melancolía; 2) histórico de pérdidas y superación; 3) negación como mecanismo de defensa en el luto; 4) luto condicionado por la culpa; y 5) depresión como reacción a la pérdida. Se destaca la importancia de estos significados como base para la actuación del profesional de la salud que trabaja con ancianos guardando luto.

Descriptores: Pesar; Anciano; Investigacion Cualitativa.

\section{Introdução}

O envelhecimento populacional ocorre no Brasil de maneira rápida, quando comparado aos países desenvolvidos, trazendo importantes consequências a todos os setores da sociedade ${ }^{(1)}$. Este aumento na proporção de idosos não ocorre igualmente entre homens e mulheres. Com o avanço da idade, o número de mulheres em relação ao de homens é maior. Além disso, boa parte delas são viúvas e encontram-se em posição de maior fragilidade e vulnerabilidade a doenças físicas, mentais e desenvolvimento de incapacidades ${ }^{(2-3)}$.

Em um contexto epidemiológico, onde a maioria da população idosa é constituída por mulheres, viúvas, convivendo em famílias nucleares, com presença de comorbidades e, muitas vezes, com a capacidade funcional prejudicada $^{(1-3)}$, a morte do marido pode agravar este conjunto de problemas, fazendo com que o luto ocorra de maneira diferente, muitas vezes mais complicada do que em pessoas não idosas ${ }^{(4)}$.

Considerando que, a maior fragilidade física entre idosos é vista como um aumento da vulnerabilidade para acometimentos à saúde, a experiência do luto em idosos pode ser vivenciada como um evento de sobrecarga, pois em idade mais avançada existe o risco de múltiplas e sequenciais perdas de familiares e amigos. Assim, a adição de mais eventos com consequências 
negativas pode ser esperado, devido à proximidade do luto a uma vasta gama de eventos estressantes associados ao envelhecimento, como enfermidades, mudança de ambiente, problemas financeiros, entre outros ${ }^{(4-5)}$.

A vivência do luto em idosos pode, comumente, transparecer como quadro depressivo ou outro transtorno ansioso e, como é característico desta população, pode apresentar formas e sintomatologias variadas ${ }^{(6)}$. Estudos de seguimento mostraram que grupos de idosos viúvos apresentaram grandes níveis de depressão, quando comparados aos não viúvos ${ }^{(7-8)}$.

Em contrapartida, o aumento da resiliência em idosos enlutados pode ser considerado um fator facilitador no enfrentamento do $1 \mathrm{uto}^{(9)}$. A resiliência é apresentada como um fenômeno, um funcionamento e, por vezes, uma arte em adaptar-se às situações adversas, desenvolvendo capacidades ligadas aos recursos internos (intrapsíquicos) e externos (ambientais), que permitem aliar construção psíquica adequada à inserção social $^{(10)}$. Dessa maneira, a superação de perdas anteriores pode levar ao desenvolvimento de um ponto de vista e um conceito de si próprio, facilitando a adaptação a perdas posteriores ${ }^{(4)}$.

É possível superar as perdas, desde que o indivíduo conte com apoio, reflexão e tratamento. A perda de um ente querido alcança níveis elevados na escala de estresse e os indivíduos que sofrem perdas tornam-se mais vulneráveis às doenças, principalmente na ocasião da perda, quando não conseguem recursos internos para superá-la ${ }^{(9)}$.

Pelo exposto, o processo de luto em idosos pode transparecer como um evento complexo e de grande impacto, tanto na saúde mental quanto física. Dessa maneira, faz-se necessária a instrumentalização dos profissionais de saúde que atuam junto a essa população, evidenciando a necessidade de compreensão das especificidades do processo de luto. Neste contexto, o presente estudo objetiva compreender os significados da vivência do luto em idosas, pela morte do cônjuge/marido.

\section{Método}

Para a presente pesquisa foi utilizado o método clínico-qualitativo, como um refinamento dos métodos qualitativos gerais. A escolha do método ocorreu pela adequação entre suas características e objetivos propostos neste estudo. O método clínico-qualitativo possibilita ao pesquisador colocar-se frente à pessoa enlutada $\mathrm{e}$ compartilhar as ansiedades e angústias advindas da vivência da perda, buscando compreensão das questões propostas e, ao mesmo tempo, identificando-se com o outro. Esta atitude existencialista, característica do método clínico-qualitativo, permite que o pesquisador acolha as angústias e ansiedades deste, possuindo, assim, uma atitude clínica, com olhos e ouvidos qualificados para compreensão existencial dos sofrimentos que acometem o outro. O método clínico-qualitativo de investigação científica busca interpretações de sentidos e significações trazidos por indivíduos, sobre múltiplos fenômenos pertinentes ao processo saúde-doença, permitindo o uso de um quadro eclético de referenciais teóricos, para discussão no âmbito da interdisciplinaridade ${ }^{(11)}$.

Para estudar fenômenos que tenham estrutura complexa, de foro pessoal (íntimo) e/ou verbalização difícil, no caso da morte do companheiro/cônjuge, a metodologia clínico-qualitativa mostra-se particularmente útil. Assim, o presente método permite a investigação aprofundada de questões íntimas e carregadas de sofrimento, o acolhimento das angústias e ansiedades desses sujeitos, em uma atitude clínica, fornecendo parâmetros eficazes para constatação da validade dos resultados.

Esta pesquisa ocorreu dentro da área de abrangência do Programa de Saúde da Família (PSF), em um município com aproximadamente 100 mil habitantes, localizado ao norte do estado do Paraná. Foi estudada uma amostra intencional, por variedade de tipos, composta por seis mulheres idosas que vivenciaram o processo de luto por morte do cônjuge, selecionadas a partir dos registros das Equipes de Saúde da Família. Os critérios de inclusão foram: a) possuir idade igual ou superior a 60 anos; b) ser do sexo feminino; c) residir em área urbana e de abrangência do PSF, do município de Arapongas, PR; d) ter vivenciado a morte do marido há mais de um mês e menos de 13 meses antes da data da entrevista; e e) concordar em participar do estudo.

Considerando as preposições do método clínico-qualitativo, o investigador serviu como 
instrumento principal de coleta e registro dos dados. Nesta concepção, são as suas percepções que apreendem os fenômenos e sua consciência que os representa e elabora. Como instrumentos auxiliares para realização da coleta de dados foram utilizados a técnica de entrevista não estruturada e observação. A análise dos dados realizou-se conforme as técnicas de análise de conteúdo, descritas especificamente para o método clínico-qualitativo ${ }^{(11)}$.

Em relação aos preceitos éticos, a presente pesquisa foi aprovada pelo Comitê de Ética em Pesquisa da UNOPAR, mediante o protocolo $\mathrm{n}^{\mathrm{o}}$ PP 0222/08, seguindo as normas e diretrizes regulamentadoras de pesquisa em seres humanos, dispostas na Resolução 196/96 CNS. Ainda, foi garantido às idosas a participação por livre e espontânea vontade e o direito de abandono da pesquisa em qualquer fase, através da assinatura do Termo de Consentimento Livre e Esclarecido.

\section{Resultados e discussão}

Os resultados obtidos nas entrevistas foram organizados em agrupamento de categorias, sem hierarquização dos dados a partir da importância presumida ou frequência de aparecimento nas falas. Do escopo total de categorias encontradas foram elencadas cinco categorias para apresentação. A escolha destas categorias ocorreu através da correlação entre temática desenvolvida e objetivos propostos. Não há pretensão de apresentação de resultados generalizáveis, além da amostra pesquisada, sendo que, as inferências e interpretações desenvolvidas referem-se, exclusivamente, ao contexto em que realizou-se a pesquisa. Porém, a reflexão destes achados pode servir de tema para reflexão na compreensão do trabalho de luto em idosos, em um contexto mais abrangente.

\section{Categoria 1. O luto e a saudade}

Uma das características mais comuns do luto não se refere à depressão profunda, mas a episódios agudos de dor, com muita ansiedade e dor psíquica $^{(6)}$. Nestas situações, o enlutado sente muita saudade da pessoa que morreu, chora ou chama por ela. A palavra saudade pode ser definida como recordação suave e melancólica de uma pessoa ausente, local ou coisa distante, que se deseja voltar a ver ou possuir ${ }^{(12)}$. A saudade oferece um referencial histórico da existência individual $^{(13)}$. Assemelha-se a um testamento da memória, uma herança da lembrança e presença na continuidade da existência dos enlutados:

[...] no começo a gente parece que tava mais conformado né, mas como tudo, mais dia passa, parece que é pior né, vai dando saudade, a gente vai sentindo a falta que ele faz [...] (Benedita).

A saudade, como traço característico do processo de luto, está atrelada a outra manifestação: a busca ou procura pelo falecido ${ }^{(6)}$. A preocupação com pensamentos sobre a pessoa perdida e acontecimentos que levaram à morte é comum em pessoas enlutadas. Estas lembranças são marcantes e a pessoa morta pode ser vista exatamente como era, ou em outras situações, a mulher enlutada pode sentir a presença ou a expectativa de que o marido "logo chegará", como se tivesse apenas saído de viagem ou algo semelhante: [...] acha falta dele na sala, acha falta aqui na mesa onde ele se sentava. Ai tem dia que a gente fica triste, desanimada, tem dia que a gente se anima mais um pouco e a vida vai passando assim [...] (Cecília).

Para muitos enlutados, especialmente aqueles que perderam companheiros de toda uma vida, datas como aniversário de nascimento, morte, Natal ou quaisquer outras datas que tenham forte relação com o falecido podem desencadear as chamadas reações de aniversário. As reações de aniversário constituem-se em fenômenos ligados ao luto, em que processos inconscientes e elucidados por fatores temporais fazem com que o indivíduo reviva situações passadas, de maneira deformada e mascarada ${ }^{(14)}$. Estas reações são elucidadas por uma data e fazem o indivíduo passar por processos variados de manifestação: ansiedade, tristeza, surtos psicóticos, somatizações, entre outros: [...] com 2 meses ainda, você tem parece que a impressão que vai voltá, que foi fazê uma viagem. Ai vai caindo, vai caindo na real que não volta, ai vem datas comemorativas, igual agora foi dia dos pais, então é barra! [...] (Dulce).

\section{Categoria 2. Histórico de perdas e resiliência}

É comumente encontrada na literatura a afirmação de que quanto mais situações de perda um indivíduo apresentar em sua vida, maior será a probabilidade de um processo de luto anormal, ou seja, o acúmulo de perdas anteriores é visto 
como um dos fatores relacionados à dificuldade em elaborar o luto ${ }^{(5-6,15)}$.

Estudos demonstram que, apesar dos idosos enlutados demonstrarem evidências de sofrimento emocional e físico, grande parte mostra-se altamente resiliente ${ }^{(16-17)}$. Neste contexto, resiliência pode estar ligada à superação de perdas passadas, facilitando à adaptação de perdas posteriores, explicando o presente resultado. Em um estudo prospectivo, $46 \%$ dos idosos apresentaram um padrão resiliente de luto, com baixos níveis de sintomas depressivos antes da morte do cônjuge e após 18 meses da perda ${ }^{(18)}$.

Estes resultados corroboram com os achados obtidos nesta pesquisa, pois a ocorrência de perdas anteriores, apesar de terem sido verbalizadas por grande parte das entrevistadas, parece não ter contribuído para pior elaboração do luto atual. Apesar de quatro das seis entrevistadas mencionarem perdas por morte de familiares e entes muito próximos, não ficou evidente que estes eventos contribuíram para a pior elaboração do luto atual. Isto é reforçado pelo fato da única viúva que apresentou indícios de má elaboração do luto não ter verbalizado, durante a entrevista, outras perdas anteriores à morte do esposo.

Outro ponto importante encontrado nesta categoria diz respeito à relação entre resiliência e crenças religiosas: [...] qué dizê que eu passei 3 luto de morte da família né, mas fazer o que?...tem que conformá com o que Deus faz... tudo que Deus faz é bom!.... Tem gente que maltrata Jesus, que Jesus não podia fazê isso, tirá filho meu, tirou meu filho mais velho, eu nunca abri a boca pra falá. Ele faz aquilo que ele qué, né! Eu ainda num sei o que vou passá, agora minha cunhada lá na UTI, num sei se ela vai morrê ou não, já entreguei nas mão de Deus [...] (Divina).

A espiritualidade revela-se como um forte indicador de resiliência, especialmente por permitir o encontro de significado na vida, a partir da fé $\mathrm{e}^{(9)}$. Vale a pena ressaltar que, a resiliência não deve ser considerada como um atributo fixo da pessoa, mas como um processo onde família, comunidade e sociedade devem prover recursos para que a pessoa possa se desenvolver mais plenamente ${ }^{(16)}$. Considerando que, a resiliência pode ser aprendida pelos indivíduos, por meio de pessoas significativas e modelares ${ }^{(9)}$, é necessário que sejam desenvolvidas estratégias específicas de enfrentamento de adversidades, como no luto, e que contemplem o fenômeno da religiosidade e espiritualidade.
Categoria 3. Negação como mecanismo de defesa no luto

A negação pode ser entendida como a recusa em reconhecer um estímulo que provoca ansiedade $^{(19)}$. A negação tem função de adiar a dor, até que a realidade torne-se inevitável, ajudando o enlutado a preparar-se para a mesma ${ }^{(6)}$. $\mathrm{O}$ uso da negação como mecanismo de defesa no processo de luto foi percebido em duas das seis entrevistadas: [...] no dia eu vou falar pra você que eu tenho pouca lembrança [...] minha cabeça se recusou a aceitar, e eu acho que quando veio a noticia pra mim foi, eu me lembro pouca coisa desse dia, e me senti muito forte né, com muita fé [...] (Dulce). [...] eu não chorei, eu não reclamei, parece que eu fiz tudo que parece que não foi eu [...] a minha sobrinha que mora em Ourinhos falo assim: 'Tia, a sua ficha não caiu ainda! A senhora ainda vai chorá muito!' [...] (Eva).

Dulce relembra com exatidão a recusa em aceitar a morte do marido no primeiro dia após a perda. A negação, como mecanismo de defesa inconsciente, é utilizada para evitar o contato com um evento de difícil aceitação. Entretanto, sentimentos podem ser evitados também de forma consciente e deliberada ${ }^{(20)}$. No entanto, dissociação, negação e repressão de um indivíduo podem ser habilidades importantes para sobrevivência e controle de traumas e perdas. Porém, a manutenção destes padrões pode ter consequências disfuncionais, configurando-se como complicadores do processo de luto ${ }^{(21)}$.

Categoria 4. O luto mediado pela culpa

A irritabilidade e a raiva no luto variam de pessoa para pessoa, família para família e períodos para períodos ${ }^{(6)}$. Às vezes, estes sentimentos são dirigidos ao próprio enlutado, como autoacusação ou culpa: [...] isso fica martelando e a gente perde o sono né... eu já sou ruim pra dormir.. e ai eu acordo e fico imaginando, aquilo fica martelando na cabeça: porque que a gente num fez isso? Porque que a gente não fez aquilo? E isso é ruim pra gente né! [...] (Benedita).

Atribuir culpa a si mesmo pode ser uma forma de proteger-se dos sentimentos de desamparo, temor de não sobrevivência psíquica, abandono e sentir-se menos impotente diante da perda e da dificuldade de construir significado a respeito $^{(22)}$. Em estudo realizado com viúvas londrinas $^{(6)}$, sete das 22 mulheres pesquisadas expressaram ideias de autorreprovação, centradas 
em alguma omissão ou ação que pudesse ter causado dano ao marido ou perturbado sua paz de espírito. Com frequência, estes eventos eram banais e sugeriam que as enlutadas procuravam se castigar, aceitando a culpa e acreditando, de alguma maneira, na reversão dos acontecimentos, para terem de volta o marido perdido: [...] ficava imaginando a gente podia tê feito isso, podia tê feito aquilo, ou o médico, foi descuido do médico que não cuido dele direito né, mas eu acho que a gente não pode ficá se culpando [...] Então a gente conversa com um, com outro, a gente não tem que se culpar, chegou o dia né, acho que a gente tem o dia da gente né! [...] (Benedita).

\section{Categoria 5. A depressão como reação à perda}

No caso do luto normal e sem complicações, a fase de busca da pessoa perdida, intensa nas primeiras semanas e meses, gradativamente vai diminuindo e dando espaço à fase de desespero, onde o enlutado reconhece a imutabilidade da perda, vivenciando apatia, desmotivação e depressão ${ }^{(20)}$.

Uma das entrevistadas relatou que, após o segundo mês da morte do marido iniciou-se um processo de depressão, rebaixamento da autoestima, desmotivação e desinteresse, levando-a a acompanhamento psiquiátrico, para uso de antidepressivos: [...] mas só que com o passar do tempo... eu fui entrando e estou [mostrou-se muito emocionada nesse momento]... e ainda estou [...] tenho passado por tratamento psiquiátrico,[...] agora faz uma semana eu já tou com outra medicação pra vê se eu reajo melhor... mas ta muito difícil pra mim [choro] [...] (Dulce).

A depressão decorrente de má elaboração do luto é vastamente descrita na literatura, com forte associação entre idade avançada e vulnerabilidade à depressão ${ }^{(4,6,23)}$. Em uma revisão de literatura $^{(23)}$ foi encontrado que, dependendo da amostra e dos procedimentos de mensuração, entre $15 \%$ e $30 \%$ dos idosos apresentaram quadros clínicos de depressão em até um ano após a morte do cônjuge e entre $40 \%$ e $70 \%$ apresentaram quadros de distimia.

O relato de Dulce deixa claro seus sentimentos de tristeza, desmotivação e baixa autoestima, como característica de um quadro depressivo, decorrente da perda do marido: [...] eu não tenho vontade de sair, não tenho vontade de me arrumar, muitos dias eu não quero nem tomar banho, só vou por obrigação mesmo. $O$ meu mundo é dentro do quartinho ali que eu tenho meu computador, e o televisor, então ali é meu mundo, eu não quero conversar, eu passo a tarde inteirinha, eu só saio mesmo pra fazer a fisioterapia, hidroterapia [...] (Dulce).

Do ponto de vista psicanalítico, a primeira aproximação entre luto e depressão está no texto clássico "Luto e melancolia" de Sigmund Freud $^{(24)}$. Nele, Freud aponta que a melancolia difere do luto normal, pela presença de baixa autoestima e autorrecriminação. Diferente do luto normal, onde a escolha do objeto é de natureza narcisista. Este objeto narcisista valoriza o sujeito em si e sua perda provoca o rebaixamento da autoestima. As críticas e acusações feitas a si, na verdade, são dirigidas ao objeto, expressando a intensa ambivalência emocional da relação. Assim, o sujeito não aceita os sentimentos hostis em relação ao objeto e se culpa por tê-lo perdido, em razão aos desejos de morte do objeto.

Ao analisar com mais afinco a história contada por Dulce, percebem-se evidências de ambivalência em seu relacionamento com o esposo falecido. Anos antes de sua morte, o marido começou a apresentar problemas de saúde e, gradativamente, foi se instalando uma forte relação de dependência. Segundo seu relato, ao mesmo tempo que sentia-se útil e valorizada nesta relação de dependência, sentimentos de irritabilidade e raiva denotam a ambivalência da relação: [...] à medida que eu fui me projetando, ele foi encolhendo, né. E ai ele foi ficando cada vez mais dependente, os assuntos era pra eu resolver, ai já passou a ele me chamá de mãe, mãe isso, mãe aquilo, né! Então, eu falta até dessa dependência, né ... na verdade me irritava aquela dependência de "mãe que horas são ... então era assim, e ele achava que era só eu que sabia, muitas vezes eu também não sabia, e ele foi ficando assim, isso me irritava, mas ao mesmo tempo agora eu me sinto inútil... sabe aquela lacuna, aquela ausência vai pesando [...] (Dulce).

Outro elemento encontrado no discurso de Dulce é o estoicismo, entendido como uma forma de manter o ego forte, na tentativa de aguentar qualquer adversidade. A conformação/resignação é uma submissão, muitas vezes, como uma rebelião silenciosa. Esta defesa é muito valorizada pela sociedade do século $\mathrm{XX}$, sendo força e silêncio da dor vistos como altamente desejáveis ${ }^{(25)}:$ [...] sempre a mãe era a mulher maravilha, $e$ foi indo, dai, a mulher maravilha deu uma despencada, e feia!... então pra mim, agora, essa época ta muito dificil [...] (Dulce). 


\section{Considerações finais}

Dentre as perdas advindas do processo de envelhecimento, o luto pela morte do cônjuge constitui-se em um evento de grande importância, devido as suas repercussões nos contextos social, emocional e saúde do idoso. Pelos achados descritos acima, é possível perceber que a saudade e a busca pelo ente querido são traços evidentes do processo de luto, e levam a episódios de muita dor, pesar e sofrimento emocional.

Neste estudo, o histórico de perdas anteriores ao luto atual, parece não ter contribuído para pior elaboração da perda. Portanto, o conceito de resiliência, onde a vivência de perdas passadas pode facilitar a superação de perdas posteriores, aplica-se à amostra estudada.

Foi evidente nos relatos a negação da perda, a raiva dirigida a si, a culpa pela perda ou não realização de alguma vontade do falecido e a depressão. Apesar destes mecanismos e respostas fazerem parte do processo de luto normal, exacerbações destes constituem-se em complicadores para elaboração da perda, e devem ser trabalhados no trato aos idosos enlutados.

Tendo em vista a alta frequência de situações de luto entre idosos e a magnitude dos problemas emocionais e físicos que tais perdas podem resultar, ressalta-se a importância de se considerar estes significados, como alicerce para atuação do profissional de saúde que trabalha com idosos.

\section{Referências}

1. Colss VE, Schwanke CHA. A evolução do índice de envelhecimento no Brasil, nas suas regiões e unidades federativas no período de 1970 a 2010. Rev Bras Geriatr Gerontol. 2012;15(3):443-58.

2. Silva VL, Albuquerque MFPL, Cesse EAP, Luna CF. Perfil de mortalidade do idoso: análise da evolução temporal em uma capital do Nordeste brasileiro de 1996 a 2007. Rev Bras Geriatr Gerontol. 2012;15(3):433-41.

3. Farinasso ALC, Marques S, Rodrigues RAP, Hass WJ. Capacidade funcional e morbidades referidas de idosos em uma área de abrangência do PSF. Rev Gaucha Enferm. 2006;27(1):45-52.
4. Hansson RO, Stroebe MS. Bereavement in late life: coping, adaptation, and developmental influences. Washington: American Psychological Association; 2007.

5. Kovács MJ. Desenvolvimento da tanatologia: estudos sobre a morte e o morrer. Paidéia (Ribeirão Preto). 2008;18(41):457-68.

6. Parkes CM, Prigerson HG. Bereavement: studies of grief in adult life. New York: Routledge; 2010.

7. Lund DA, Casserta MS, Dimond MF. Impact of spousal bereavement on the subjective well-being of older adults. In: Lund DA. Older bereaved spouses: research with practical implications. New York: Taylor and Francis/Hemisphere; 1989. p. 3-15.

8. Carnelley KB, Wortman CB, Kessler RC. The impact of widowhood on depression: findings from a prospective survey. Psychol Med. 1999;29(5):1111-23

9. Silva AI, Alves VP. Envelhecimento: resiliência e espiritualidade: história de vida de idosos: superar a adversidades sem perder o senso de integridade. Diálogos Possíveis. 2007;6(1):189-209. 10. Laranjeira CASJ. Do vulnerável ser ao resiliente envelhecer: revisão de literatura. Psicol Teoria Pesq. 2007;23(3):327-32.

11. Turato ER. Tratado da metodologia da pesquisa clínico-qualitativa. 4ed. Petrópolis: Vozes; 2010.

12. Ferreira $\mathrm{ABH}$. Dicionário Aurélio da Língua Portuguesa. 5ed. Curitiba: Ed Positivo; 2010.

13. Paula B. Corpos enlutados: por um cuidado espiritual terapêutico em situações de luto [tese]. São Paulo: Faculdade de Humanidades e Direito/ UMESP; 2009. 370 p.

14. Cassorla RMS. O tempo, a morte e as reações de aniversário. In: Cassorla RMS. Do suicídio: estudos brasileiros. Campinas: Papirus; 1991. p. 107-16.

15. Oliveira JBA, Lopes RGC. O processo de luto no idoso pela morte do cônjuge e filho. Psicol Estudo. 2008;13(2):217-21.

16. Laranjeira CASJ. Do vulnerável ser ao resiliente envelhecer: revisão de literatura. Psicol Teoria Pesq. 2007;23(3):327-32.

17. Lund DA, Casserta MS, Dimond MF. The course of spousal bereavement in late life. In Stroebe MS, Stroebe W, Hansson RO, editors. Handbook of bereavement: theory, research and 
intervention. Cambridge: Cambridge University

Press; 1993. p. 240-54.

18. Fry PS. Predictors of health-related quality of life perspectives, self-steem, and life satisfactions of old adults following spousal loss: an 18-month follow-up study f widows and widowers. Gerontologist. 2001;(41):797-8.

19. Friedman HS, Shustack MW. Teorias da personalidade: da teoria clássica à pesquisa moderna. São Paulo: Prentice Hall; 2004.

20. Bowlby J. Formação e rompimento dos laços afetivos. São Paulo: Martins Fontes; 1979.

21. Walsh F, McGoldrick M. A perda e a família: uma perspectiva sistêmica. In: Walsh F, McGoldrick M, editors. Morte na família: sobrevivendo às perdas. Porto Alegre: Artmed; 1998. p. 27-55.

22. Mazorra L. A construção de significados atribuídos à morte de um ente querido e o processo de luto [tese]. São Paulo: Departamento de Psicologia Clínica da Pontifícia Universidade Católica; 2009. 253 p.

23. Carr D. Factors that influence late-life bereavement: considering data from the changing lives o folder couples study. In: Stroebe MS, Hansson RO, Schut H, Stroebe W, editors. Handbook of bereavement research and practice: advances in theory and intervention. Washington: American Psychological Association; 2008. p. 417-40.

24. Freud S. Luto e Melancolia. In: Freud S. Edição standart brasileira das obras completas de Sigmund Freud. Rio de Janeiro: Imago; 1974. 25. Kovacs MJ. Morte em vida. In: Bromberg MHPF. Vida e morte: laços de existência. São Paulo: Casa do Psicólogo; 1996. p. 11-34. 